\title{
QUEEN'S
UNIVERSITY
BELFAST
}

\section{Social Work and Social Media: Online Help-Seeking and the Mental Well-Being of Adolescent Males}

Best, P., Manktelow, R., \& Taylor, B. J. (2016). Social Work and Social Media: Online Help-Seeking and the Mental Well-Being of Adolescent Males. British Journal of Social Work, 46(1), 257-276.

https://doi.org/10.1093/bjsw/bcu130

\section{Published in:}

British Journal of Social Work

\section{Document Version:}

Peer reviewed version

Queen's University Belfast - Research Portal:

Link to publication record in Queen's University Belfast Research Portal

\section{Publisher rights}

(c) The Author 2014. Published by Oxford University Press on behalf of The British Association of Social Workers. All rights reserved.

This is a pre-copyedited, author-produced PDF of an article accepted for publication in British Journal of Social Work following peer review. The version of record [Best, P, Manktelow, R \& Taylor, BJ 2016, 'Social Work and Social Media: Online Help-Seeking and the Mental WellBeing of Adolescent Males' British Journal of Social Work, vol 46, no. 1, pp. 257-276 is available online at:

http://bjsw.oxfordjournals.org/content/46/1/257

\section{General rights}

Copyright for the publications made accessible via the Queen's University Belfast Research Portal is retained by the author(s) and / or other copyright owners and it is a condition of accessing these publications that users recognise and abide by the legal requirements associated with these rights.

Take down policy

The Research Portal is Queen's institutional repository that provides access to Queen's research output. Every effort has been made to ensure that content in the Research Portal does not infringe any person's rights, or applicable UK laws. If you discover content in the

Research Portal that you believe breaches copyright or violates any law, please contact openaccess@qub.ac.uk. 


\section{Abstract}

Current global concerns regarding the mental well-being of young males have called for fresh approaches to social work service delivery. This study investigates the efficacy of adopting more 'online' approaches within social work practice by examining the current impact of online help-seeking behaviours on the mental wellbeing of adolescent males. A survey questionnaire comprised of validated scales measuring mental well-being and self-efficacy, combined with questions examining online help-seeking attitudes and behaviours was completed by 527 respondents aged 14-16 years within a school environment. The internet was used by $42 \%$ of respondents to retrieve health information. In general, respondents appeared knowledgeable regarding the importance of trusted and quality online health information, yet were more likely to use search engines (57\%) or social networking sites (48\%) to find information rather than a government sponsored website (23\%). Young males who reported speaking to online friends regarding personal problems recorded statistically significantly higher levels of mental wellbeing $(p<0.02)$. This may suggest that being able to communicate online how you are feeling is a positive for male mental health. Social work practitioners need to recognise this generational shift in help-seeking, in terms of providing and commissioning interpersonal helping via social media.

Key Words: Help-seeking; Social Media; Young People; Wellbeing; Internet 


\section{Introduction}

Popular discourse within social work policy and practice has focused on the need for increased access to services, early intervention approaches and more effective methods of engaging with hard-to-reach populations (Bamford Review, 2006; DoH, 2011). One such population are young males, whom despite concerted efforts by social work professionals, continue to find it difficult to access services and receive support (Rickwood et al., 2007; Campbell et al., 2013). This paper investigates how emerging technologies are changing the way individuals seek help and support and thus considers the changing role of the social work professional within this new environment.

The internet and social media technologies (SMT) have created a multitude of opportunities and risks for service users and social workers alike (Valkenburg et al., 2006; BASW Social Media Policy, 2012). While there is little doubt that increased access to information afforded through these technologies has created great benefits, commentators have highlighted the poor quality of information available online and the possibility of negative help-seeking behaviours encouraged through informal online communities (Andersson et al., 2011; Henderson et al., 2012).

This paper addresses a number of key issues for social work practice and policy in regards to this area. Firstly, the reported dramatic increase in the level of mental illhealth amongst young people is a central concern for the social work profession with figures suggesting one in five may experience mental health problems (WHO, 2012). Consequently, early intervention and the effective identification of risk are seen as crucial if these emotional difficulties are to be prevented developing into serious mental illness (Bamford Review, 2006; DoH, 2011; Taylor and Campbell, 2011). 
Secondly, traditional Tier One (Bamford, 2006) Community Adolescent Mental Health Services (CAMHS) have found it notoriously difficult to engage young people because of stigma, ignorance and peer pressure. Online provision can bypass these obstacles and offer an immediate response in an area of practice where resources are stretched and long waiting lists commonplace.

Using a sample population of adolescent males, this paper reports the use of the internet and SMT to facilitate help-seeking and the possible influences upon Mental Wellbeing (MWB).

\section{Literature Review}

While recent social work literature has begun to examine the potential of the internet and SMT to inform and assist social work practice (Dodsworth et al., 2013; Masson et al., 2013) the area remains largely unexplored with little research involving large cohorts of potential service users. In spite of this, the potential benefits of online technologies for social work practice continues to be postulated (e.g. increased opportunity for service user participation and self-disclosure) if not yet acted upon (Tregeagle and Darcy, 2008). This has led some to argue that social work professionals are in danger of trapping themselves "in a twentieth-century mind-set (relying on postal addresses and landline numbers) when their study respondents [and clients] are using twenty-first-century means of communication" (Masson et al., 2013, p. 37).

In tandem with a historical reluctance to embrace new 'online' technologies (Steyaert and Gould, 2009), there seems to be a disconnection between professional concerns regarding the adoption of this technology and the growing research evidence reporting its potential benefits. This is despite a report by The British Association of 
Social Workers (BASW) on the benefits of SMT for social work practice (BASW Social Media Policy, 2012). Spurred by the limited dissemination of high quality research, social work professionals may have adopted a risk avoidance attitude, perhaps reinforced by media and organisational warnings of the dangers of social media.

While the use of SMT among social work practitioners is often discouraged, key institutions such as the Social Care Institute for Excellence (SCIE) (http://www.scie.org.uk/) and the Department of Health (DoH) (http://digitalhealth.dh.gov.uk/) in the UK have, to some extent, attempted to harness the power of social media by creating social networking profiles (e.g. Facebook, Twitter and LinkedIn), perhaps reflecting the vital importance of starting to use these media to promote health and social wellbeing.

The Bamford Review (2006) of mental health and learning disability provision in Northern Ireland recognised of the need for more early intervention services (Bamford, 2006). This was a response to the increasing evidence suggesting better psycho-social outcomes associated with earlier intervention (Sainsbury Centre for Mental Health, 2003; Bamford, 2005; Stafford, 2013). In the UK context the 'No Health without Mental Health' (DoH, 2011) strategy outlined early intervention approaches as one of the key areas for prioritisation. Yet the difficulties of targeting young people at risk of mental ill-health are exacerbated by the fact that few have a registered psychiatric history. Further evidence suggests that among those who experience a life time of mental health difficulties, the first episode or symptoms often occur by the age of 14 (Kim-Cohen, 2003). Online technologies may facilitate a faster transition into services for vulnerable young people and thus allow earlier treatment for mental health problems. This however must be tempered with concerns 
regarding the threat to "profession authority" expressed by social workers through the adaption of more online modes of service delivery (Dodsworth et al., 2013, p. 793).

\section{Adolescent Males}

There is a body of research which postulates help-seeking as influenced by gender, and that girls are generally more active help-seekers than boys (Rickwood and Braithwaite, 1994). Theories of masculinity provide concepts to understand these findings. 'Masculinity' is defined by Gilmore (1990) as the "approved way of being an adult male in any given society". Some basic and stereotypical characteristics of masculinity are strength, courage, intelligence and self-reliance (Harland, 2000; Lusher and Robins, 2010). Courtenay (2003, p. 7) notes that "males who adopt traditional or stereotypic beliefs about masculinity have greater health risks than their peers with less traditional beliefs". This evidence suggests that certain masculine 'values' (self-reliance, strength) prohibit men and boys from seeking help regarding mental illness, thus impacting upon wellbeing. Young males may therefore be considered high risk of mental ill-health due to gender role conflicts that place barriers on help seeking behaviour. Help-seeking is not merely visiting a doctor but is a process by which one is 'aware' and 'responds to' ill-health in terms of social and cultural practices (Farrimond, 2011, p. 2). Features of the internet, such as increased confidentiality and anonymity, may therefore appeal to young males in terms of help-seeking.

\section{Help-Seeking}

Help-seeking can be viewed as a process or mechanism of coping that may relieve an individual's uncomfortable psycho-emotional state (Rickwood and Braithwaite, 
1994). This complex activity appears influenced by both gender and age and thus, to some extent, culturally and biologically engineered (Ishikawa et al., 2010). As such, help-seeking attitudes and behaviours between individuals may differ greatly. While help-seeking is viewed largely as positive, the mere notion of 'seeking help' connotes diminished self-reliance and may be a difficult psychological barrier to overcome, particularly for males (Corrigan, 2004; Storrie et al., 2010). A review of barriers to help-seeking among young people identified the following factors as influential: negative attitudes towards help seeking; concerns regarding cost and inconvenience; confidentiality; feeling they can handle it themselves; not knowing where to go; stigmatisation; preference for informal networks e.g. family and friends (Gulliver et al., 2010, p. 5).

For the purposes of this study help-seeking is viewed as twofold, involving both formal and informal practices. Informal help-seeking is more common and usually occurs between family and friends. Formal help-seeking is less common and usually involves some sort of professional intervention (Young, Giles and Plantz's, 1982; Setiawan, 2006). Formal professional intervention is often reported as a more effective form of support for serious and complex mental health issues (Martin, 2002; Greenburg et al., 2001). However, young people in particular tend not to seek professional help and instead rely on informal networks (Rickwoood et al., 2005). Consequently, these networks may not provide the level of support necessary and thus certain issues remain unresolved. Further to this are cases of suicidal ideation where evidence suggests that young people do not confide in informal networks either, thus limiting both forms of intervention (Rickwood et al., 2005). Often when suicidal ideation increases, help seeking decreases - therefore those in suicidal 
crisis may not want, or wish, to seek help. This process is known as 'help-negation' (Carlton and Deane, 2000).

Help-Seeking and Technology

This paper was informed, in part, by the theoretical framework of help-seeking developed by Rickwood and colleagues (2005) following their comprehensive review of empirical research in the area (see figure 1). This useful aid was designed as an intra-psychic process model of help-seeking based within the individual rather than structural level. It provides a valuable framework in which to conceptualise and evaluate the efficacy of online technologies within the help seeking process.

\section{Figure 1}

Despite vigorous debate within the field, a number of studies have postulated the mental health support benefits of online technologies (Mackinnon et al., 2008; Barak and Grohol, 2011; Burns et al., 2013). Murphy and colleagues (2009, p. 635) in a comparative study of both online and face to face counselling reported that "cybercounselling [was] equivalent in impact to face to face counselling".

Online technologies have been shown to be fast, accessible, low cost and confidential. In spite of this, we know relatively little of the mental well-being outcomes of online help-seeking. Best et al (2013, p. 2) note that online "support services may serve to reduce the potential emasculating consequences of stigmatising face-to-face help seeking, thus appealing to males in particular". This suggests that young males may favour this form of service yet in the same study the authors produced evidence suggesting a dearth of high quality online support. The apparent lack of quality information and support has created 'trust' issues with online 
services, a key component in any effective help-seeking process (Rickwood 2007; Gulliver et al., 2010). It is considered therefore that accessing mental health support online may result in inaccurate advice or diagnosis, perhaps increasing the potential for harm.

Burns et al (2013) examined the wellbeing and online help-seeking practices of older males (16 - 25), reporting that the majority utilised search engines rather than specific websites to locate health information. Moreover, the authors found an association between increased psychological distress and increased use of the internet. Those reporting moderate to high psychological distress were also more likely to talk to others through the internet regarding their problems. Interestingly, the authors also noted the high number of distressed individuals accessing online resources after $11 \mathrm{pm}$, perhaps suggesting the need for more online professional support outside of regular office hours.

An early study by Mead et al (2003) investigated factors which may influence individual interest in using the internet as a health resource. The authors found the following to be likely indicators; (1) positive outcome expectancy; (2) previous use of health websites; (3) positive self-efficacy; (4) higher education; (5) level of social deprivation and (6) having school age children at home. Of particular interest is selfefficacy as a determinant of online help-seeking behaviours. Self-efficacy (SE) relates to beliefs concerning one's ability to perform certain actions and tasks (Bandura, 1999). Early studies have shown that a lack of confidence in ones' ability can lead to poorer coping attitudes and behaviours (Williams and Kleinfelter, 1989). Perceived confidence or 'self-efficacy' may be a factor in both an individual's decision to seek help or the medium they choose to obtain such help. While many young males may not have the required self-efficacy to seek help face-to-face, they 
may have the confidence with computers to seek help online. Burns et al (2009) found that for those who used ReachOut.com, a successful mental health service, they had increased awareness and understanding of how to help themselves as well as increased contact with mental health professionals.

Research Questions

The following research questions were developed from the literature in this area and helped shape the research methodology and analysis;

- To what extent do adolescent males use online resources to access health information and support?

- Do males who use the internet for health related purposes find it easier to use online mental health services?

- What is the impact of using the internet for health information on MWB?

- Does disclosure of problems to others influence MWB?

- What is the impact of online friends on help-seeking behaviour?

- What factors predict help-seeking behaviours in adolescent males?

\section{Methodology}

Research Design

The sample population for the study was adolescent males aged 14-15 attending secondary education within Northern Ireland (NI). A 48-item questionnaire was 
administered within seven schools using a clustered random sampling technique (Bryman, 2004). This cohort was chosen for the following reasons: -

- They are an 'at risk' age group as evidenced by the current high levels of suicide within the adolescent male population in $\mathrm{NI}$;

- Gender specific differences in help-seeking behaviour are well reported;

- This sample is one of the first cohorts to have 'grown up' with online social networking technology.

Accessing this population through secondary schools provided a viable means of access as well as appropriate support mechanisms in case of distress caused by taking part. Schools were recruited within four of the five Educational and Library Boards ensuring geographical representativeness. The potential number of survey participants was approximately 700 using this sampling strategy.

Table 1 shows some of the socio-demographic variables associated within the school sample: 
Table 1

\begin{tabular}{|c|c|c|c|c|c|c|}
\hline & Secondary & Grammar & $\begin{array}{l}\text { Single } \\
\text { Gender }\end{array}$ & $\begin{array}{l}\text { Co- } \\
\text { Educational }\end{array}$ & Urban & Rural \\
\hline School A & $\checkmark$ & & $\checkmark$ & & $\checkmark$ & \\
\hline School B & $\checkmark$ & & & $\checkmark$ & & $\checkmark$ \\
\hline School C & & $\checkmark$ & $\checkmark$ & & & $\checkmark$ \\
\hline School D & $\checkmark$ & & $\checkmark$ & & $\checkmark$ & \\
\hline School E & & $\checkmark$ & & $\checkmark$ & $\checkmark$ & \\
\hline School F & $\checkmark$ & & $\checkmark$ & & $\checkmark$ & \\
\hline School G & $\checkmark$ & & $\checkmark$ & & $\checkmark$ & \\
\hline
\end{tabular}

The questionnaire incorporated a number of validated measures as outlined below.

Ethical approval for the project was granted by the University of Ulster Research Governance Committee and informed written consent was gained from each participant.

Measures

Mental Wellbeing (MWB)

The questionnaire included the 'Warwick-Edinburgh Mental Wellbeing Scale' (WEMWBS) a validated instrument used in previous research (Tennant et al., 2007; Devine and Lloyd, 2012). This scale was "developed to capture a broad concept of positive mental well-being...including psychological functioning, cognitive-evaluative dimensions and affective-emotional aspects" (Beaumont and Thomas, 2012, p. 17). The WEMWBS uses a 5 point Likert scale and includes 14 positively worded 
statements. Scores range from $14-70$ with higher scores indicating higher mental well-being. WEMWBS has Cronbach Alpha scores of 0.91-0.93 indicating high internal consistency (Tennant et al., 2007).

Social Networking and Internet Use

The 'Social Networking' section was developed by the authors from previous research within the field, following a rigorous systematic search of current evidence (Best et al., 2014). This included studies that have examined social networking and internet use among children as young as 10 years old as well as studies which have developed specific measures of social networking intensity (see Ellison et al., 2007; ARK, 2009; Neill et al., 2011). Examples of items from this section are as follows; how many online friends do you have....? or how long do you spend viewing your social networking account on an average day....? These questions were presented using a collection of ranges (e.g. 10mins - 20mins) and Likert type scales (Never Always).

\section{Self-Efficacy}

The Self-Efficacy section was created using the 'General Self-Efficacy Scale' (GSE) (Schwarzer and Jerusalem, 1995). This is a validated instrument consisting of 10 items and scored using a 4 point scale. In samples from 26 countries Cronbach's alpha's for this scale ranged from $0.76-0.90$ with the majority in the high 0.80 s (Schwarzer and Jerusalem, 1995).

Online Help-Seeking

Questions concerning online help-seeking attitudes and behaviours were developed through a series of scoping exercises including a review of online mental health 
services (Best et al., 2013) as no suitable tool could be identified for this domain. This section of the questionnaire included questions on informal and formal online help-seeking (e.g. have ever shared personal problems with online friends or have you ever used online mental health services...). Questions were asked on the participant's knowledge of existing online services and the likelihood of using them. The latter involved a five point likert scale ( $1=$ Very Unlikely to $5=$ Very likely). Scores ranged from $6-30$, with higher scores denoting more active online searching.

Analysis

Statistical analysis of the data was conducted using SPSS v20.0 (Pallant, 2004). The following tests reported in this paper include chi-square for independence, t-tests, analyses of variance and standard linear regression for correlational analyses. Confidence Intervals for all tests were at 95\%.

\section{$\underline{\text { Results }}$}

The final total of participants was 527 with a high overall response rate of $77 \%$, owing to the fact the researcher was present and delivered the questionnaires within schools.

To what extent do adolescent males use online resources to access health information and support?

Results showed that 218 respondents (42\%) used the internet to retrieve health information. The majority of this group $n=126(57 \%)$ used it for information on physical health whereas a lesser proportion $n=65(29 \%)$ used it for mental health information. When asked how they would locate this information online; search engines, $n=294(57.2 \%)$ and social networking sites $n=250(48.9 \%)$ achieved the 
highest responses. Only $122(23.8 \%)$ stated they were likely to use NHS (National Health Service) or local government websites (see table 2).

Table 2

\begin{tabular}{lc}
\hline Online Help Seeking & Percentage \\
\hline
\end{tabular}

Online resource used

Search engine $\quad 57.4^{*}$

Social Networking Site 48.9*

Generic Website with some health 23.8*

information

NHS or Government Health website 23.8*

Online Professional 18.3*

Health Website (directly) 17.6*

Note* - Results are given from those who answered 'Likely - Very Likely'

Approximately a quarter of the entire sample $n=134(25.8 \%)$ stated they would find online services 'easier to use than speaking to someone face to face'. Participants were then asked to rate by importance (not very important to very important) key features which they felt online mental health services should incorporate (see table 3). 
Table 3

\begin{tabular}{l}
\hline Recommended features of Online Percentage \\
Mental Health Services
\end{tabular}

Feature

70.4*

Professionally trained staff

63.9*

Anonymity

53.0*

The ability to text/type feelings

53.0*

'Chat' Based Facility

49.7*

Interactive Content

43.3*

Link to it through SNS**

$28.8^{*}$

Note* - Results are given from those who answered 'Important - Very Important'

Note** - SNS (Social Networking Site)

These results suggest that 'knowing the information came from a trusted source' and the constant presence of a 'trained professional' were the most importance features of online mental health services.

Offline help-seeking remains the most popular avenue of support with 287 (54\%) of respondents stating they would share personal problems solely with 'offline' friends. However, a significant number of participants $n=142(27 \%)$ stated they would disclose important personal problems with both 'offline and online' friends.

A quarter $n=54(25 \%)$ of young males who sought out health information online stated 'they wouldn't tell anyone'. Interestingly, over $40 \%$ of this sub-sample stated 
they would find online services easier to use. Important features of online mental health services are given in Table 4 for this group.

Table 4

\begin{tabular}{l}
\hline Important Feature - Respondents Percentage \\
who wouldn't disclose personal \\
problems
\end{tabular}

Feature

Trusted Source

$74.2^{*}$

Professionally trained staff

64.9*

Anonymity

$60.3^{*}$

'Chat' Based Facility

$55.4^{*}$

The ability to text/type feelings

46.6*

Interactive Content

$44.8^{*}$

Link to it through SNS

$22.8^{*}$

Note* - Results are given from those who answered 'Important - Very Important'

Note* - Results are taken from those who answered 'Important - Very Important' and who stated they would not tell others regarding personal problems

In comparison with the wider sample, this sub-group placed particular value on anonymity as evidenced through the high percentage $n=35(60.3 \%)$ in this category as well as the lower percentage $n=13(22.8 \%)$ recorded in the link to it through 
social networking site' (SNS) category. This group was also more likely to use search engines $n=40(70.2 \%)$ to locate health information than the wider sample.

Do males who use the internet for health related purposes find it easier to use online mental health services?

A chi-square test for independence found a significant difference between participants using the internet to find health information and a preference for using online mental health services, $X^{2}(1, n=520)=4.811, p=0.02$, phi $=0.101$. Further testing using Spearman's Rho suggested a significant positive correlation between the two variables $(\rho=.105, n=526, p=0.017)$. Therefore those who used the internet to find health information were more likely to show a preference for using online mental health services.

What is impact of using the internet for health information or support on MWB?

An independent samples t-test was conducted to compare the difference in MWB scores for those who used the internet for health information and those who did not. There was no significant difference in scores between groups $(t=-1.513$; $d f=518$; $p=0.113)$. Therefore searching online for health information was not associated with decreases in MWB among respondents.

\section{Does disclosure of problems to others influence MWB?}

As reported above, $25 \%$ of participants who searched online for information regarding personal problems stated they 'wouldn't tell anyone'. A one-way between groups analysis of variance was conducted to investigate the impact this may have on MWB. Subjects were divided into groups according to how or when they 
disclosed problems (Group 1: would search online but not disclose problems to others; Group 2; would search online before disclosing problems to others; Group 3 would disclose face-to-face and search online afterwards for more information).

There was a statistically significant difference $(p=0.001)$ in MWB scores across the three disclosure groups: $F(2,246)=9.31, p=0.001$. However, despite reaching statistical significance the difference in means was relatively small. The effect size, calculated using eta squared, was .07. Post-hoc comparisons (Tukey HSD test) indicated the mean scores for Group $1(M=49.09, S D=8.89)$ were significantly different from Groups $2(M=52.42, S D=8.99)$ and Group $3(M=54.32, S D=5.98)$. Group 2 did not differ significantly from Group 3 (see graph below). Therefore respondents who stated 'they wouldn't tell anyone' had lower mean MWB scores (see graph 1).

Graph 1

\section{What is the impact of online friends on help-seeking behaviour?}

Social media technology allows one to communicate with and build large informal networks online. Spearman's Rho showed significant positive correlations between the number of online friends and increased help-seeking practices, including the use of social media to find health information $(\rho=.317, n=510, p=0.001)$ and discussing problems with friends online $(\rho=.320, n=511, p=0.001)$. There was also small significant difference in the MWB of those who confided regularly with friends online and those who did not $(t=-4.070 ; d f=247 ; p=0.001)$.

\section{What factors predict help-seeking behaviours in adolescent males?}


Using variables listed in previous work (see Mead, 2003 above) a standard linear regression analysis was performed. While the ANOVA showed the overall model as significant $F(4,502)=3.676, p=0.006$, the total variance explained by all four variables was only $2.8 \%\left(\mathrm{R}^{2}=.028\right)$. In fact, as the regression table (see table 5) shows the only significant contributor to the model was previous use of the internet for health information. Self-efficacy, social economic background and educational level were not significant predictors of online help-seeking behaviour.

Table 5: Results of multiple regression analysis $(n=501)$ 
SES

Self-Efficacy

Grammar/Secondary Education

Previous use of the internet for health

$\mathbf{R}^{2}$
.628

.059

.700

$-.030$

846

.250

$.150 *$

${ }^{*} p<.01$

${ }^{a}$ Dependent variable - Likely to use online resources scale (Very Unlikely= 1 to Very Likely= 5)

Further to this, a greater number of variables were put into the regression model covering a range of behavioural, socio-demographic and psychological factors (see table 6). Again, while the ANOVA showed the overall model as significant: $F(12,449)$ $=2.241, p=0.009$, the total variance explained by these 12 variables was only $5.6 \%$ $\left(\mathrm{R}^{2}=.056\right)$. The only significant predictor in the model was the activity of 'posting comments on social networking profiles'. The likeliness of using online resources for health was not significantly predicted by MWB, time spent online or geographical location.

Table 6: Results of multiple regression analysis - demographic, behavioural and psychological variables $(n=$ 449) 
Urban/Rural

SES

Grammar/Secondary Education

Do you have a SNS account

Time spent online per day

Online Activity

Social Networking

School Work

Chat to Strangers

Download Music/Videos

Posting Comments

Mental Wellbeing

Self-Efficacy

$\mathbf{R}^{2}$

$\mathbf{F}$
$-1.126$

.223

.397

1.500

.436

$-4.087$

.461

.165

1.411

2.024

.049

.011

.056
.737

$-.089$

.654

.021

.847

.034

1.315

.059

.596

.035

.246

$-.089$

.680

.032

507

.015

.907

.077

$.127 *$

.860

.079

0.31

.008

$* p<.01$.

${ }^{a}$ Dependent variable - Likely to use online resources scale (Very Unlikely= 1 to Very Likely= 5)

\section{Discussion}

\section{Limitations}


It must be firstly acknowledged that many of the effect sizes reported in this study were small despite statistical significance; therefore further research in this area is needed. It is also recognised that while the sample population are the same age they may not be at the same development stage (Devine and Lloyd, 2012) therefore various confounding developmental factors may have influenced the answers given.

\section{Using online resources to seek help}

In accordance with previous research, online health information and support seeking remains a popular activity among young people (Oh et al., 2008; Burns et al., 2009; Fox, 2011). This form of help-seeking may involve searching for information via specific or generic websites or seeking support through online communities and networks of friends. As mental ill-health remains a stigmatising condition the potential of these online utilities to provide confidential access to information or support for those who would not otherwise seek help must not be under estimated (Thronicroft, 2006; Szumilas and Kutcher, 2009). A caution, however, must be raised regarding the means through which information is accessed online by young males i.e. via search engines and social networking sites. Additionally, less than a quarter of respondents stated they would be likely to access mental health information through government health websites, a topic worthy of further study in its own right. This is an interesting juxtaposition considering the importance given to features of online mental health services such as, "knowing the information came from a trusted source' and the 'presence of trained professionals'. Statutory health and social care bodies may seek to address this issue by increasing their 'online presence' both through increased marketing and the development of appropriate services. 
The evidence gathered suggests that young males value mental health services run by trained professionals such as social workers available 24 hours a day - a difficult task to achieve. These types of services are currently lacking within statutory health and social care websites (Best et al., 2013). As a consequence young males tend to rely on search engines and social networking sites to steer them towards appropriate resources. While these methods may be faster and more convenient, search algorithms are based on the query inputted not quality of service provided, hence young people may be receiving erroneous and potentially harmful advice (Dolowitz, et al., 2008). A targeted campaign on social media platforms as well as increased visibility through search engine displays may be appropriate first steps to addressing the low usage of government-based health and social care websites.

\section{The efficacy of online mental services to support male mental health}

The results showed no significant impact between the online help-seeking habits of individuals from areas of high versus low socio-economic status or urban versus rural localities, suggesting a low risk of marginalising particular groups if social workers develop services using social media. However, a large proportion of young males reported that they do not disclose personal problems or difficulties to others. This 'hard to reach' and vulnerable sub-group appear to favour anonymity and online 'chat' options even more so than the wider sample group, perhaps highlighting the particular appeal of online services for this population. While not without limitations, non-statutory online help-seeking through the internet and social media technology may represent the only viable avenue of support available to some young males.

A key message for practice from this study is that online mental health websites should develop more 'chat' based technologies with the aim of encouraging more 
young males to avail of social work services. While the data shows that some males may not disclose problems to others, they are in fact receiving some form of support through help-seeking practices online. Consequently, even when small effect sizes are obtained, the statistical significance of results in this area still indicates clinical importance for the social work profession, particularly for those to whom offline helpseeking is a bridge too far. The challenge therefore is to ensure the services available are of a high quality and number to meet this demand.

\section{Explaining the mental health benefits of online help-seeking}

Online technologies may have increased help-seeking behaviours among young males due to confidentiality and anonymity benefits (Szumilas and Kutcher, 2009; Callahan and Inckle, 2012). This process can be conceptualised through the Rickwood et al., (2005) help-seeking model as beneficial during both the 'expression' and 'availability' stages resulting in an increased willingness to seek help. The reduction in social stigma afforded by this process allows young males to search freely for health information on a range of personal issues without having to disclose to others. Yet in spite of this, it is difficult to ascertain whether or not this behaviour is impacting upon mental well-being. In order to tease this issue out further the researchers tested the MWB scores of individual's by way of disclosure type following online help seeking (see above). The results indicated that those who use online help seeking as a supplement to offline help seeking may gain the greatest mental health benefits. Hence, it may be more beneficial to use both online and offline resources, rather than one resource alone. The efficacy of online technologies as a supplement to existing offline services has also been suggested in research undertaken with other service user groups, such as foster carers (see Dodsworth et al., 2013). 
One of the unique aspects of this study was the consideration of the impact of online social networking technology on online help-seeking. The results have shown that SNS are used both to search for health information as well as provide opportunities for informal support through 'online friends'. The ability to amass a larger number of so called 'weak' ties (Granovetter, 1973) online may be providing young males with an additional outlet to seek social support. The results tend to support this hypothesis by showing higher MWB scores attributed to those who have larger online friend networks or who have confided in online friends regarding personal problems. These findings appear to support the body of literature associating online social networking with increased bridging capital and the subsequent mental health benefits (Ellison et al., 2007; Ahn, 2012). Future research may seek to establish the particular nuances and MWB implications of both formal and informal online helpseeking.

No significant predictive capacity was found between educational attainment, SES and help-seeking - unsurprising given the vast increases in internet access since the Mead et al., (2003) study. Self-efficacy was not found to be a significant predictor of help seeking; however there may be a number of reasons for this. Higher SE has been associated with increases in social network support and positive relationships thus these individuals may feel more comfortable seeking out face-to-face support (Holahan and Holahan, 1987; Bandura, 1999). Moreover, it may be that those who have higher perceived SE feel confident in their own coping abilities and thus do not seek help at all. More research on the identification and targeting of vulnerable populations unlikely to seek help offline may prove valuable.

\section{Conclusions}


The call for the social work profession to utilise online technologies within their practice is timely given current moves by policy makers to reform social work education (see Narey, 2014). It is clear that this new environment is one that social workers are being drawn more and more towards, whether in terms of additional sign-posting to services or as intelligence gathering vehicles. As such, "social workers need to be aware of and knowledgeable about technological developments and understand [their] impact, use and advantages" (BASW Social Media Policy, 2012, p. 5).

Social work practitioners would do well to recognise the generational shift in helpseeking and begin to increase their knowledge of quality online mental health services available during 'out of office' hours. Of particular relevance was the positive associations found between online help-seeking and mental well-being. These findings suggest that using the internet to supplement offline help seeking is more beneficial to mental well-being than using the internet alone. Therefore increased help-seeking outlets and opportunities provided through online technologies seem to be positive for adolescent male mental health. Higher numbers of online friendships indicated more help-seeking behaviours, suggesting some benefit from these types of social networks. In spite of this, a word of caution must be directed at the quality of support provided through informal systems, such as lower quality websites, for more serious mental health issues.

This study provides evidence suggesting a lack of engagement by young males with government health and social care websites, and therefore much work is required to address the quality issues surrounding internet health information. In spite of this online mental health services provide appear to provide inclusive approach to service delivery, being readily available and easily accessible by a large number of 
potential service users amongst the younger generation. This is a developing approach to service delivery which social work as a profession must address more rigorously in the future.

\section{Funding}

This research received no specific grant from any funding agency in the public, commercial or not-for-profit sectors. However the first author is in receipt of a PhD studentship funded through the Department of Employment and Learning (NI).

\section{$\underline{\text { References }}$}

Ahn, J. (2012) Teenagers' Experiences with Social Network Sites: Relationships to Bridging and Bonding Social Capital, The Information Society: An International Journal, 28(2), pp. 99-109 
Andersson, G., Ljotsson, B. and Weise, C. (2011) Internet-delivered treatment to promote health. Current Opinion in Psychiatry, 24(2), pp. 168-172.

ARK. Kids' Life and Times survey, 2009 [computer file]. ARK http://www.ark.ac.uk/kltwww.ark.ac.uk/klt [distributor], October 2009

Bamford Review of Mental Health and Learning Disability (2005) Department of Health, Social Services and Public Safety (DHSSPS).

Bamford Review of Mental Health and Learning Disability (NI) (2006) A vision of a comprehensive childhood and adolescent mental health service. Department of Health, Social Services and Public Safety (DHSSPS)

Bandura, A. (1999). Self-efficacy: Toward a unifying theory of behavioral change. In R. F. Baumeister (Ed.), The self in social psychology. Key readings in social psychology, pp. 285-298. Philadelphia, PA. Psychology Press.

Barak, A. and Grohol, J.M. (2011) Current and future trends in internet-supported mental health interventions. Journal of Technology in Human Services, 29(3), pp. 155-196.

Beaumont, J. and Thomas, J. (2012) Measuring National Wellbeing. Health Office for National Statistics (ONS).

Best, P., Foye, U., Taylor, BJ., Hazlett, D. and Manktelow, R. (2013) Online interactive suicide support services: Quality and accessibility. Mental Health Review Journal, 18(4), pp. 226-239 [doi: http://dx.doi.org/10.1108/MHRJ-03-2013$\underline{0009]}$ 
Best P, Manktelow R. and Taylor BJ. (2014) Online Communication, Social Networking and Adolescent Wellbeing: A Systematic Narrative Review. Children and Youth Services Review. 41, pp. 27-36. [doi: org/10.1016/j.childyouth.2014.03.001]

Burns, J., Durkin, L. and Nicholas, J. (2009) 'Mental health of young people in the United States: what role can the internet play in reducing stigma and promoting help-seeking?', Journal of Adolescent Health, 45(1), pp. 95-7.

Burns, J.M., Davenport, T.A., Christensen, H., Luscombe, G.M., Mendoza, J.A., Bresnan, A., Blanchard, M.E. and Hickie, I.B. (2013) Game On: Exploring the Impact of Technologies on Young Men's Mental Health and Wellbeing. Young and Well CRC. Melbourne.

Callahan, A. and Inckle, K. (2012) Cybertherapy or psychobabble? A mixed methods study of online emotional support. British Journal of Guidance and Counselling, 40(3), pp. 261-278.

Campbell, J., Rondon, J., Leavey, G. and Galway, K. (2013) Meeting the needs of vulnerable young men: A study of service provider views. Children and Society, $27,60-71$.

Carlton, P.A. and Deane, F.P. (2000) Impact of attitudes and suicidal ideation on adolescents' intentions to seek professional psychological help. Journal of Adolescence, 23, pp. 35-45.

Corrigan, P. W. (2004) How stigma interferes with mental health care. American Psychologist, 59, pp. 614-625. 
Courtenay, W.H. (2003) Key determinants of the Health and Well-Being of men and Boys. International Journal of Men's Health, 2(1), pp. 1-27.

Devine, P. and Lloyd, K. (2012) "Internet use and psychological well-being among 10-year-old and 11-year-old children.", Child Care in Practice, 18(1), pp. 5-22.

Department of Health (DoH). (2011) 'No Health Without Mental Health' Implementation Framework. Department of Health. Accessed 24 July 2012

Department of Health (DoH) Digital guidance and best practice for the health and care system. Available at http://digitalhealth.dh.gov.uk. Accessed 3rd October 2013

Dodsworth, J., Bailey, S., Schofield,G., Cooper, N., Fleming, P. and Young, J. (2012) Internet technology: an empowering or alienating tool for communication between foster-carers and social workers? British Journal of Social Work, 2, pp. $1-21$

Dolowitz, D.P., Buckler, S. and Sweeney, F. (2008) Researching Online. Palgrave: USA.

Ellison, N.B., Steinfield, C. and Lampe, C. (2007) The Benefits of Facebook "Friends:" Social Capital and College Students' Use of Online Social Network Sites. Journal of Computer-Mediated Communication. 12, pp. 1143-1168.

Eysenbach, G. (2001) What is e-health? Journal of Medical Internet Research, 3(20).

Farrimond, H. (2011) Beyond the caveman: Rethinking masculinity in relation to men's help-seeking. Health DOI: 10.1177/1363459311403943 
Fox, S. (2011) Health Topics. Pew Research Center's Internet and American Life Project. http://pewinternet.org/Reports/2011/HealthTopics.aspx

Gilmore, D.D. (1990) Manhood in the Making: Cultural Concepts of Masculinity. Yale University Press, New Haven, CT.

Granovetter, M. (1973) The Strength of Weak Ties. American Journal of Sociology. 78(6) $1360-1380$

Greenberg, M.T., Domitrovich, C. and Bumbarger, B. (2001) The prevention of mental disorders in school-aged children: Current state of the field. Prevention and Treatment, 4, pp. 1-58.

Gulliver, A., Griffiths, K.M. and Christensen, H. (2010) Perceived barriers and facilitators to mental health helpseeking in young people: a systematic review. BMC Psychiatry, 10, 113.

Harland, K. (2000) Men and masculinity: an ethnographic study into the construction of masculine identities in inner city Belfast. PhD submitted to the University of Ulster.

Henderson, E. M., Rosser, B. A., Keogh, E. and Eccleston, C. (2012) Internet sites offering adolescents help with headache, abdominal pain, and dysmenorrhea: A description of content, quality, and peer interactions. Journal of Pediatric Psychology, 37(3), pp. 262-271.

Holahan, C. K. and Holahan, C. J. (1987) Self-efficacy, social support, and depression in aging: A longitudinal analysis. Journal of Gerontology, 42, pp. 6568. 
Ishikawa, R.Z., Cardemil, E.V. and Falmagne, R.J. (2010) Help Seeking and Help Receiving for Emotional Distress Among Latino Men and Women. Qualitative Health Research, 20(11), pp. 1 - 15

Kortum, P., Edwards, C. and Richards-Kortum, R. (2008) The impact of inaccurate internet health information in a secondary school learning environment. Journal of Medical Internet Research, 10(2), pp. 17.

Kim-Cohen, J., Caspi, A., Moffitt, T., Harrington, H., Milne, B. and Poulton, R. (2003) Prior juvenile diagnoses in adults with mental disorder. Archives of General Psychiatry, 60, pp. 709-717

Lusher, D. and Robins, G. (2010) A social network analysis of hegemonic and other masculinities. Journal of Men's Studies, 18(1), pp. 22-44.

Mackinnon, A., Griffiths, K.M. and Christensen, H. (2008) Comparative randomized trial of online cognitive-behavioural therapy and an information website for depression: 12-month outcomes. British Journal of Psychiatry, 192, pp. 130-4.

Martin, G. (2002) The prevention of suicide through lifetime mental health promotion: Healthy, happy young people don't suicide, do they? In L. Rowling, G. Martin and L. Walker (Eds). Mental Health Promotion and Young People: Concepts and Practice. McGraw-Hill, Sydney.

Masson, H., Balfe, M., Hackett, S. and Phillips, J. (2013) Lost without a trace? Social networking and social research with a hard-to-reach population. British Journal of Social Work, 43(1). pp. 24-40. ISSN 0045-3102 
Mead, R., Varnam, A., Rogers, M. and Roland, M. (2003) What predicts patients' interest in the Internet as a health resource in primary care in the Internet as a health resource in primary care in England? Journal health services research policy. 8(1), pp. 33-39.

Murphy, L. M., Parnass, P., Mitchell, D. L., Hallett, R. H., Cayley, P. and Seagram, S. (2009) Client satisfaction and outcome comparisons of online and face to face counselling methods. British Journal of Social Work. 39, pp. 627-640

Narey, M. (2014) Making the education of social workers consistently effective: Report of Sir Martin Narey's independent review of the education of children's social workers. Available at https://www.gov.uk/government/uploads. Accessed 12th June 2014

Pallant, J. (2004) Spss Survival Manual 4th Edition. McGraw-Hill Education.

Oh, E., Jorm, A.F. and Wright, A. (2008) Perceived helpfulness of websites for mental health information. Social Psychiatry and Psychiatric Epidemiology, 44, pp. 293-9.

O'Neill, B., Livingstone, S. and McLaughlin, S. (2011) Final recommendations for policy, methodology and research. LSE, London: EU Kids Online.

Rickwood, D.J. and Braithwaite, V.A. (1994) Social-psychological factors affecting seeking help for emotional problems. Social Science and Medicine, 39, pp. 563572.

Rickwood, D., Deane, F., Wilson, C. and Ciarrochi, J. (2005) Young people's helpseeking for mental health problems. Australian e-Journal for the Advancement of Mental Health, 4(3). 
Rickwood, D., Deane, F. and Wilson, C. (2007) When and how do young people seek professional help for mental health problems? Medical Journal of Australia, 187, pp. 35-39.

Sainsbury Centre for Mental Health (2003) A window of opportunity: A practical guide for developing early intervention in psychosis services. London: Sainsbury Centre for Mental Health.

Social Care Institute for Excellent SCIE (SCIE). Available at http://www.scie.org.uk/. Accessed 20th September 2013.

Schwarzer, R. and Jerusalem, M. (1995) Generalised Self-Efficacy Scale. In J.Weinman, S. Wright and M. Johnston. Measures in health psychology: A user's portfolio. Causal and control beliefs. pp. 35 - 37. Windsor, UK: NFER-NELSON.

Setiawan, J, L. (2006). Willingness to seek counselling, and factors that facilitate and inhibit the seeking of counselling in Indonesian undergraduate students, British Journal of Guidance and Counselling, 34(3), pp. 403-419,

Stafford, M.R., Jackson, H., Mayo-Wilson, E., Morrison, A.P. and Kendall, T. (2013) Early interventions to prevent psychosis: systematic review and meta-analysis. British Medical Journal. 346, pp. 185. doi: 10.1136/bmj.f185

Steyaert, J. and Gould, N. (2009) 'Social work and the changing face of the digital divide', British Journal of Social Work, 39(4), pp. 740-53.

Storrie, K., Ahern, K. and Tuckett, A. (2010) A systematic review: Students with mental health problems--a growing problem. Interantional Journal of Nursing Practice, 16(1), pp. 1-6. 
Szumilas, M. and Kutcher, S. (2009). Teen Suicide Information on the Internet: A Systematic Analysis of Quality. Canadian Journal of Psychiatry, 54(9), pp. 596604.

Taylor, B.J and Campbell, B. (2011) Quality, risk and governance: Social Workers' perspectives. International Journal of Leadership in Public Services, 7(4), pp. 256272. [doi: $\underline{10.1108 / 17479881111194152]}$

Tennant, R., Hiller, L., Fishwick, R., Platt, S., Joseph, S., Weich, S., Parkinson, J., Secker J. and Stewart-Brown, S. (2007) The Warwick-Edinburgh Mental Wellbeing Scale (WEMWBS): development and UK validation. Health and Quality of Life Outcomes, 5(63) doi:10.1186/1477-7525-5-63

The British Association of Social Workers (BASW) (2012) Social Media Policy. Birmingham: BASW.

Thornicroft, G. (2006) Shunned: Discrimination against people with mental illness. Oxford University Press.

Tregeagle, S. and Darcy, M. (2008) 'Child welfare and information and communication technology: Today's challenge', British Journal of Social Work, 38(8), pp. 1481-98.

Valkenburg, P.M., Peter, J. and Schouten, A.P. (2006) "Friend Networking Sites and Their Relationship to Adolescents' Well-Being and Social Self-Esteem.", CyberPsychology and Behavior, 9(5), pp. 584-590.

Williams, J. G. and Kleinfelter K. J. (1989). Perceived problem-solving skills and drinking patterns among college students. Psychological Reports. 65, pp. 12351245. 
World Health Organisation (WHO) (2012) Adolescent Mental Health Mapping actions of nongovernmental organizations and other international development organizations. ISBN 9789241503648

Young, C. E., Giles, D.W. and Plantz, M. C. (1982) Natural networks: Help-giving and help-seeking in two rural communities. American Journal of Community Psychology, 10, pp. 457-469. 